\title{
DENSIFICATION PROCESS OF LOOSELY DEPOSITED SAND BED UNDER A SERIES OF OSCILLATING WATER PRESSURE
}

\author{
Yuezeng $\mathrm{YU}^{1}$, Hitoshi $\mathrm{INO}^{2}$ and Hiroshi $\mathrm{NAGO}^{3}$ \\ ${ }^{1}$ Member of JSCE, Dr.Eng., Eight Consultants Co., Ltd. \\ (3-1-21, Tsushima-Kyomachi, Okayama 700-8617, Japan) \\ e0041227@8con.co.jp \\ Member of JSCE, M.Eng., Institute of Technology, Penta-Ocean Construction Co.,Ltd \\ (1534-1, Yonku-cho, Nishinasuno-machi, Nasu-gun, Tochigi 329-2746, Japan) \\ Hitoshi.Ino@mail.penta-ocean.co.jp \\ 3 Member of JSCE, Dr.Eng., Professor, Dept. of Environmental \& Civil Engineering, Okayama University \\ (3-1-1, Tsushima-Naka, Okayama 700-8530, Japan) \\ hnago@cc.okayama-u.ac.jp
}

\begin{abstract}
The densification process of the loosely deposited sand bed that has once liquefied under oscillating water pressure on its surface is investigated by using the vertically one-dimensional model. In the analysis, the elasto-plasticity of the sand bed skeleton, the sedimentation in the liquefied sand bed and the liquefaction ratio are taken into account. The experimental results verified that the proposed analytical model expressed the dynamical behavior of sand bed through the process from the occurrence of liquefaction to the densification of the sand bed fairly well.
\end{abstract}

Key Words : liquefaction, pore water pressure, effective stress, loose sand, densification.

\section{INTRODUCTION}

When a series of oscillating water pressure acts on the surface of a loosely deposited sand bed, the sand bed is liquefied under certain conditions with the increase of pore water pressure and the decrease of effective stress.

Nago et al. ${ }^{1)}$ classified the liquefaction process of a loosely deposited sand bed into the first stage of liquefaction and the second stage of liquefaction through the study of the pore water pressure measured in the sand bed (as shown in Fig.1).

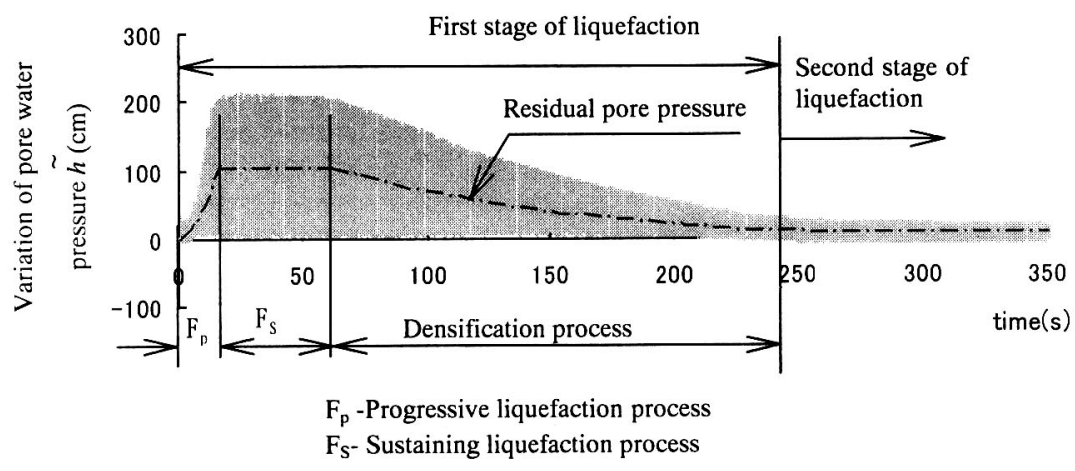

Fig.1 Pore water pressure measured in the loose sand bed 
The first stage of liquefaction is the sustained liquefaction in which the excess pore pressure includes both oscillatory pore pressure and residual pore pressure. This stage of liquefaction appears with the build-up and the fall-down of residual pore pressure in the initial period of cyclic loading.

The second stage of liquefaction is the cyclic transient liquefaction with the damping of amplitude and the lag of phase in the pore water pressure, which occurs after the first stage of liquefaction. In this stage, the sand bed has become denser, and the excess pore pressure contains only oscillatory pore pressure.

The first stage of liquefaction is composed of three parts, that is, progressive liquefaction process with the increase of the residual pore pressure( $\mathrm{Fp}$ in Fig.1), sustaining liquefaction process without the damping in amplitude and lag in phase of oscillatory pore pressure(Fs in Fig.1), and densification process with the dissipation of the residual pore pressure.

The second stage of liquefaction has been studied by many researchers, and the mechanism of the second stage of liquefaction has been well known. In last thirty years, studies are carried out under such assumptions that the pore-fluid is compressible and the sand skeleton is the poro-elastic material.

Yamamoto et al. ${ }^{2)}$ have treated for a saturated seabed of infinite depth with isotropic permeability, Madsen $^{3)}$ for that with anisotropic permeability and Okusa $^{4)}$ for unsaturated submarine sediment with the assumption of plane strain conditions of uniform elastic material.

Sakai ${ }^{5)}$ graphically showed the applicability of three solutions for the transient wave-induced pore water pressure in seabed: the seepage flow solution, the exact solution and the boundary region approximation solution of Biot's consolidation equations, by the non-dimensional parameter for surf zone conditions

$\mathrm{Nago}^{6}$ ) built basic equations describing the dynamic behavior of sand bed with one-dimensional model. In the equations, the effect of pore air is considered.

Nago and Maeno ${ }^{7}$ investigated the influences of factors related to oscillating water pressure and property of sand bed on the pore water pressure and effective stress, and made clear that the effect of pore air is notable.

Zen et al. ${ }^{8)}$ investigated the liquefaction problem related to oscillatory pore pressure with onedimensional model.

Oka et al. ${ }^{9)}$, Kuwabara and Tamai ${ }^{10)}$, Sekiguchi et al. ${ }^{11)}$ investigated the response of sand bed to wave based on the assumptions that the pore-fluid is compressible and the sand skeleton is an elastoplastic material.

Sekiguchi et al. ${ }^{11)}$ derived a closed-form solution related to the wave-induced pore pressure variation in sand bed through the assumption about plastic volumetric strain.

For preventing the destruction of the hydraulic structures built on a loosely deposited sand bed under the oscillating water pressure, it is very important to investigate the varying processes of pore water pressure and effective stress in the first stage of liquefaction. In the literature ${ }^{12)}$, the progressive liquefaction process of the loosely deposited sand bed under initial two cycles of oscillating water pressure is investigated theoretically and experimentally with the vertically one-dimensional model. In that paper, the elastoplastic model is proposed for the theoretical treatment and proved to be fairly good by the measured results. Since the above mentioned analysis was focused into the very short initial time period of excitation, the sedimentation of sand in the liquefied zone was neglected.

In this paper, the densification process of the loosely deposited sand bed, which has been once liquefied under a series of oscillating water pressure, is treated theoretically and experimentally by using the vertically one-dimensional model. The first stage of liquefaction including progressive liquefaction process, sustaining liquefaction process and densification process is comparatively long. Therefore, the sedimentation of sand and the porosity variation of sedimentary sand layer have to be taken into account in the analysis. Considering this point, the concepts of both the recovery velocity and the liquefaction ratio are applied in the following analysis.

\section{THEORETICAL INVESTIGATION}

\section{(1) Definition of excess pore pressure}

The vertically one-dimensional sand bed under the oscillating water pressure $h_{v}$ on the surface is shown in Fig.2, in which the pore water pressure varies with $h_{\nu}$. Under certain conditions ( the effective stress becomes zero ), the upper sand layer is liquefied, that is, the sustaining liquefaction zone as $y_{* 0}$ shown in Fig.2 is formed,. The pore water pressure in sand bed can be expressed with the following formula derived in the literature ${ }^{12)}$.

$$
h=h_{0}+y+\frac{(1-n)\left(\rho_{s}-\rho_{w}\right)}{\rho_{w}} y_{* 0}+h_{v}+h^{\prime}
$$


where,

$h:$ total pore water pressure in sand bed in water head

$h_{0}:$ the water depth of still water level

$y \quad:$ the depth from the initial sand bed surface

$\rho_{w}:$ density of water

$\rho_{s} \quad$ : density of an individual sand grain

$n \quad:$ porosity in sand bed

$y_{* 0}:$ the depth of the liquefied sand layer with the state of mixing fluid

$h^{\prime}$ : oscillatory excess pore pressure in water head

Transforming the above equation, the variation of pore water pressure $\tilde{h}$ at depth $y$ in sand bed can be described as ,

$$
\tilde{h}=\tilde{h}^{(1)}+\tilde{h}^{(2)}
$$

in which,

$$
\begin{gathered}
\tilde{h}=h-h_{0}-y \\
\tilde{h}^{(1)}=\frac{(1-n)\left(\rho_{s}-\rho_{w}\right)}{\rho_{w}} y_{* 0} \\
\tilde{h}^{(2)}=h_{v}+h^{\prime}
\end{gathered}
$$

$\tilde{h}$ denotes the variation portion of pore water pressure. $\tilde{h}^{(1)}$ represents the residual pore pressure which is caused by the effective weight of mixture fluid in the upper liquefied zone and $\tilde{h}^{(2)}$ expresses the oscillatory pore pressure which cyclically varies around the residual pore pressure with time.

The expression of oscillatory excess pore pressure $h^{\prime}$ at depth $y$ is obtained from the Eqs.(2)(4)(5).

$$
h^{\prime}=\tilde{h}-\frac{(1-n)\left(\rho_{s}-\rho_{w}\right)}{\rho_{w}} y_{*_{0}}-h_{v}
$$

\section{(2) Governing equations}

A vertically one-dimensional sand bed model is used to study the dynamic behavior of a loosely deposited sand bed under oscillating water pressure.

The below assumptions were introduced in the sand bed model.

1) The sand bed is composed of sand grains, water and air. The porosity of sand bed $n$ contains both the porosity occupied by pore water $n_{w}$ and the porosity occupied by air $n_{a}$.

2) The sand bed is highly saturated; therefore, the air content is considered to be very small. That is, $n_{a} \ll<$ and $n_{w} \approx n$.

3) The skeleton of the sand bed is deformed in accordance with Hooke's law. Water is compressible, but the sand grains are uncompressible.

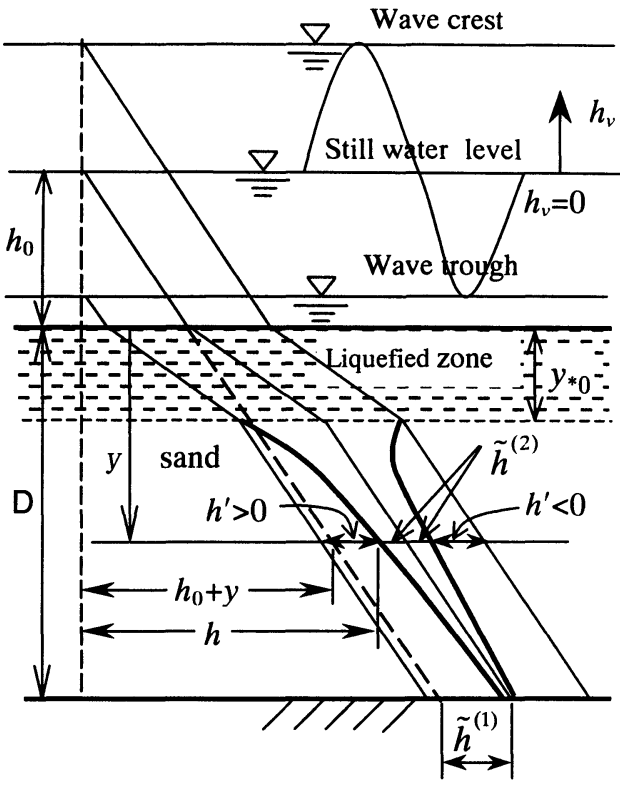

Fig.2 Excess pore pressure in sand bed

4) The volume change of pore air abides by Boyle's law and the motion of pore water abides by Darcy's law.

The system of governing equations has been derived in the literature ${ }^{12}$ under the above assumptions. It is rewritten in the following:

$$
\left.\begin{array}{c}
\frac{1}{\alpha} \frac{\partial^{2} \tilde{u}}{\partial y^{2}}=\rho_{w} g \frac{\partial \tilde{h}}{\partial y} \\
\rho_{w} g\left(\beta n_{w}+\frac{n_{a}}{P}\right) \frac{\partial \tilde{h}}{\partial t}+\frac{\partial}{\partial t}\left(\frac{\partial \tilde{u}}{\partial y}\right)=k \frac{\partial^{2} \tilde{h}}{\partial y^{2}}
\end{array}\right\}
$$

where,

$$
\begin{array}{ll}
\tilde{u} & : \begin{array}{l}
\text { displacement of sand layer (not including } \\
\text { the initial displacement) }
\end{array} \\
\alpha & : \text { elastic compressibility of the skeleton of } \\
& \text { sand bed } \\
\beta \quad: \text { compressibility of water } \\
n_{w}: \text { porosity occupied by water } \\
n_{a}: \text { porosity occupied by air } \\
P \quad: \text { absolute pressure }\left(P=P_{0}+\rho_{w} g h\right) \\
P_{0}: \text { atmospheric pressure } \\
k \quad: \text { permeability coefficient of sand bed } \\
g \quad: \text { acceleration due to gravity } \\
y \quad: \text { depth from the initial sand bed surface } \\
t \quad: \text { time }
\end{array}
$$

The system of equations (7) is taken as the governing equation of the following analysis. $\tilde{u}$ and $\tilde{h}$ in Eq.(7) are the unknown variables.

The following equation Eq.(8) has been derived 
from the equilibrium equation between the effective stress and the pore pressure in the sand bed.

$$
\sigma_{y}+\rho_{w} g h^{\prime}=\left(\rho_{s}-\rho_{w}\right) g\left(y-y_{* 0}\right)(1-n)
$$

where,

$$
\sigma_{y}: \text { effective stress. }\left(\sigma_{y}=\tilde{\sigma}_{y}+\sigma_{y 0}\right)
$$

$\sigma_{y 0}:$ the part of effective stress caused by the weight of sand particles

$\tilde{\sigma}_{y}:$ the effective stress increment induced by the excess pore pressure.

The boundary conditions of sand bed at the upper surface of the un-liquefied sand layer $\left(h^{\prime}=0\right)$ and the bottom of sand bed (impermeable, fixed) are as follows:

$$
\left.\begin{array}{l}
\tilde{h}=\frac{(1-n)\left(\rho_{s}-\rho_{w}\right)}{\rho_{w}} y_{*_{0}}+h_{\nu} \text { at } y=y_{* 0} \\
\frac{\partial \tilde{h}}{\partial y}=0, \quad \tilde{u}=0 \text { at } y=D
\end{array}\right\}
$$

At the beginning of excitation, the excess pore pressure and the liquefaction don't occur in the sand bed. Then, the initial condition is given in the following:

$$
y_{* 0}=0, \tilde{h}=0, \quad \text { at } \mathrm{t}=0
$$

When the oscillating water pressure is exerted on the sand surface, the system of basic equations (7) applied to the un-liquefied sand layer are solved under boundary conditions (9) and initial condition (10) to find $\tilde{h}$ and $\tilde{u}$.

Finite element method is applied with respect to spatial differentiation, and finite difference method is applied with respect to time differentiation.

Excess pore pressures at nodes are calculated by Eq.(6) with the pore water pressure $\tilde{h}$ determined from Eq.(7) .

Then, the effective stress can be calculated by using the above Eq.(8), when excess pore pressure $h^{\prime}$ is known.

If the stress $\sigma_{y}$ at some position deeper than the liquefied zone $\left(y_{0}\right)$ becomes zero, the corresponding liquefaction depth $y_{*}$ can be also obtained from Eq.(8).

\section{(3) Theoretical treatment}

\section{a) Elasto-plastic model}

Considering that the porosity in loosely deposited sand bed is rather large (about 0.48 at initial state), the elasto-plastic model ${ }^{12)}$ is applied in the following analysis (see Fig.3). The elasto-plastic concept of this model is summarized as follows:

Equation (7) is built on the base of the assumption that the skeleton of sand bed is deformed as elastic

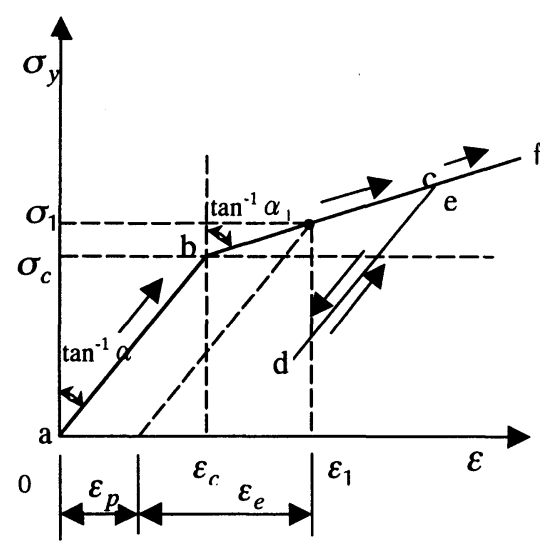

Fig.3 Stress-strain relationship for sand skeleton

material. In the numerical analysis, the elastic compressibility $(\alpha)$ of the skeleton of sand bed in the equation(7) is substituted by the plastic compressibility $\left(\alpha_{1}\right)$ after the effective stress of an element of sand exceeds the yield effective stress of the sand bed, according to the effective stress-strain relationship of sand bed skeleton.

The yield effective stress $\sigma_{c}^{\prime}$ in non-dimensional form was introduced in the former paper ${ }^{12)}$. It was defined that:

$$
\sigma_{c}=\sigma_{c}^{\prime} \times\left(\rho_{s}-\rho_{w}\right) g\left(y-y_{*_{0}}\right)(1-n)
$$

Since the analysis in the literature ${ }^{12)}$ was focused into the initial two cycles of excitation, it is very short period. Therefore, the action of sedimentation and the variation of porosity of sand bed were neglected. In this analysis, the whole process of the first stage of liquefaction of interest is comparatively long. The variation of porosity must be considered. The yield effective stress $\sigma_{c}^{\prime}$ is considered to have a relation with the porosity, therefore the yield effective stress $\sigma_{c}^{\prime}$ should vary with the variation of the porosity. The relation between the yield effective stress $\sigma_{c}^{\prime}$ and the porosity is not yet clear. Here, it is supposed for the sake of convenience that

$$
\sigma_{c}^{\prime}=N-M \times n_{w}
$$

$M, N$ are the coefficients, which are determined by trial referring the results of the model tests.

\section{b) Liquefaction ratio}

The depth $\left(y_{*_{0}}\right)$ where the effective stress in the sand bed becomes zero is calculated by Eq.(8), and it is called as the liquefaction depth above. With respect to the loosely deposited sand bed $\left(n_{w}\right.$ is about 0.48 ), the sand layer above this liquefaction depth is liquefied and is completely converted into the mixed fluid composed of sand and water. With the progress 


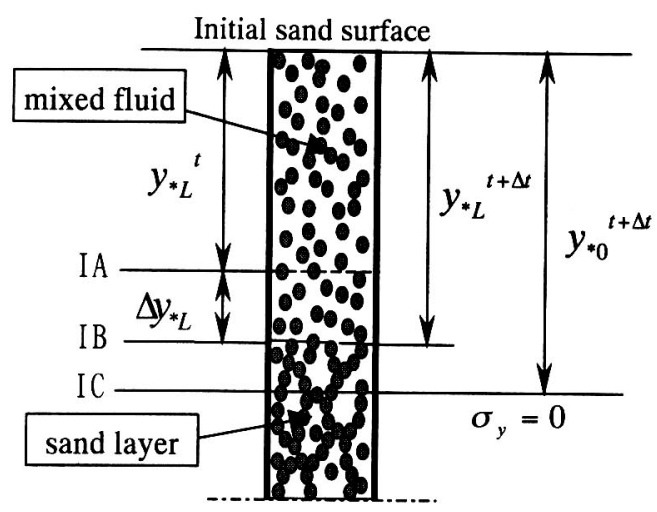

Fig.4 Definition of liquefaction ratio

of liquefaction, the sand layer is gradually densified. Then, the porosity in the sand layer decreased. As to the sand layer having the smaller porosity, the sand layer above the liquefaction depth can be partly converted into the mixed fluid. When the liquefaction progresses to the second stage of liquefaction (cyclic transient liquefaction), the porosity near the surface of sand bed becomes about 0.40 in our experiments. According to the measured pore water pressures, it is understood that the sand layer above the liquefaction depth $\left(y_{*_{0}}\right)$ is not converted into the mixed fluid in the second stage of liquefaction.

Considering the above phenomenon, the ratio of the depth increment of mixed fluid $\left(y_{* L}{ }^{t+\Delta t}-y_{*}{ }^{t}\right)$ to the increment of the liquefaction depth $\left(y_{* 0}{ }^{t+\Delta t}-y_{* L}{ }^{t}\right)$ in time interval $\Delta t$ is defined as liquefaction ratio. The liquefaction ratio is denoted by $R_{L}$. That is,

$$
R_{L}=\frac{\left(y_{* L}{ }^{t+\Delta t}-y_{* L}{ }^{t}\right)}{\left(y_{* 0}{ }^{t+\Delta t}-y_{* L}{ }^{t}\right)}
$$

where, $y_{* L}{ }^{t}$ and $y_{* L}{ }^{t+\Delta t}$ show the depth of mixed fluid at time $t$ and at time $(t+\Delta t)$, respectively. IA and IB point out the position of interface at time $t$ and at time $(t+\Delta t)$, respectively. $y_{*}{ }^{t+\Delta t}$ is the liquefaction depth at time $(t+\Delta t)$ at which the effective stress becomes zero. (refer to Fig.4)

The liquefaction ratio is considered to have the relation with the sand bed condition and the oscillating pressure, as porosity of sand bed, amplitude and frequency of oscillating pressure. Now, we have not the enough data from experiment. Therefore, the formula of $R_{L}$ is assumed to be the next equation (as shown in Fig.5):

$$
R_{L}=E \times n_{w}-F
$$

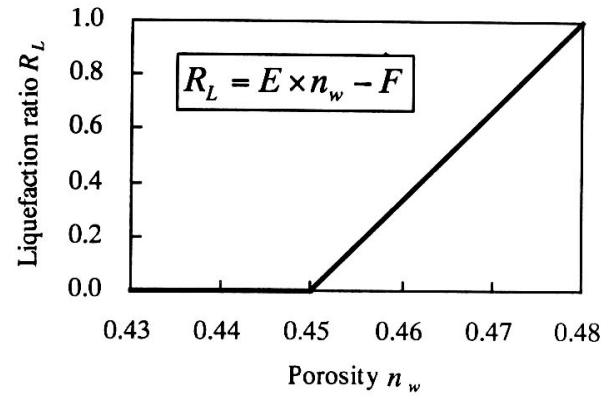

Fig.5 Liquefaction ratio with porosity $n_{w}$

and

$$
\begin{array}{lll}
R_{L}=1.0 & \text { for } & n_{w}=0.48 \\
R_{L}=0 & \text { for } & n_{w}<n_{w 2}
\end{array}
$$

where,

$E, F$ : the coefficients relating to the sand bed and the oscillating pressure.

$n_{w 2}:$ the porosity near the surface of sand bed at the beginning of the second stage of liquefaction (here, being assumed as 0.45 when $\mathrm{a}_{0}=80 \mathrm{~cm}$ )

The average of porosity $n_{w}$ between IA and IC in Fig.4 is adopted as the computation value of the porosity $n_{w}$ in Eq.(14).

c) Recovery velocity

The oscillating water pressure exerted on the sand bed surface is displayed in Fig.6(1). Under the oscillating water pressure, sand bed begins to be liquefied when certain conditions are satisfied. Once sand bed is liquefied and the mixed fluid comes about in the liquefied zone, the sand in the mixed fluid begins the sedimentation motion. It is considered that the liquefaction only occurs while the oscillating water pressure decreases ((A) to (B) in Fig.6 (1)), and the sedimentation mainly emerges while the oscillating water pressure increases ((B) to (C) in Fig.6 (1)). The position of interface between the mixed fluid zone and the lower sand layer is determined by the comprehensive effect of both liquefaction and sedimentation. During the progressive liquefaction process (see Fig.1), the amount of liquefaction is larger than that of sedimentation. So, the liquefaction develops to the deeper sand layer. When the amounts of two actions is equal, the liquefaction depth reaches its maximum value. Then, in the period of densification process the amount of sedimentation becomes larger than that of liquefaction. As a result, the interface of sand bed gradually rises until the surface of sand bed. In Fig.6 (2), (A) shows the sand bed being liquefied to 


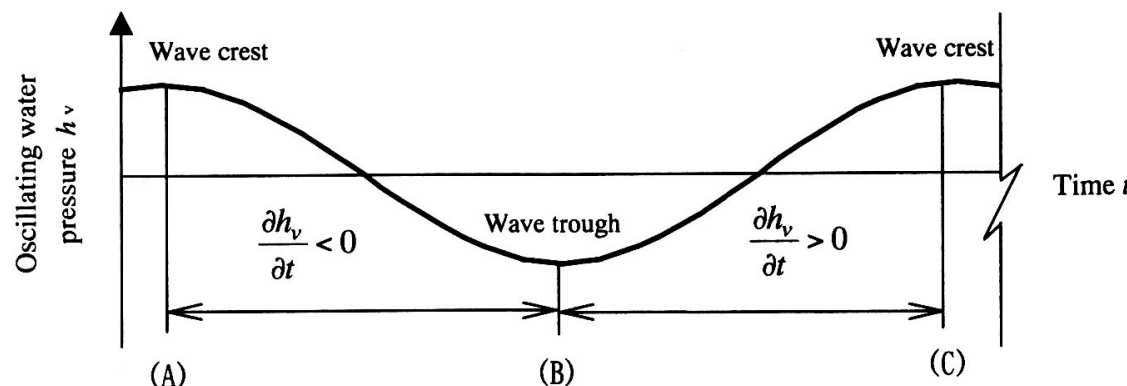

(A)

(B)

(1) Variation of oscillating water pressure on sand bed surface

Initial sand surface

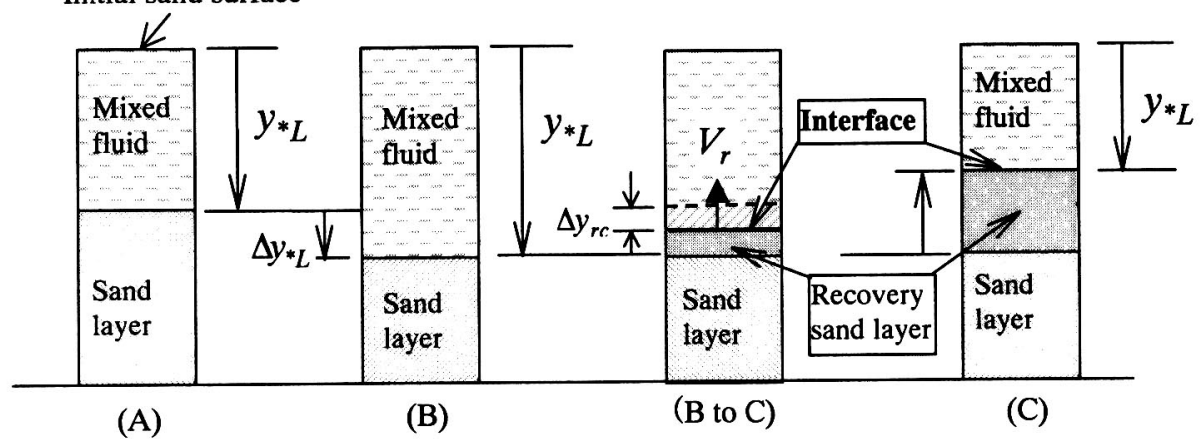

(2) Diagram of liquefaction and sedimentation in sand bed

Fig.6 Interface variation due to liquefaction and sedimentation

some extent. (B) displays the sand bed having experienced the liquefaction process of half cycle. (B to C) expresses that the interface moves up due to the sedimentation of sand in the mixed fluid zone. (C) illustrates the state of the interface after both half cycle of the liquefaction process and half cycle of the sedimentation process.

A recovery velocity is introduced here to express the upward velocity of interface between the mixed fluid and the sedimentary sand layer due to the sedimentation of sand in the liquefied zone.

In our experiment, the pore water pressures in water and at different depths of sand bed were continuously measured with pressure transducers, and were automatically saved into the large capacity of disk in the digital form. Then, the recovery time of sand layers at the different measure points can be understood from the graph of the recorded pore water pressure. The recovery velocity of sand layer was decided from the recovery time obtained above and the positions of the measurement points. The recovery velocity is considered to be mainly related to $a_{0}, f, g, y_{*}$ after the dimensional analysis on the above data. The empirical formula for the calculation of recovery velocity $V_{r}$ is obtained as follows:

$$
V_{r}=\left[0.0015 \times\left(\frac{g}{a_{0} f^{2}}\right)+0.0081\right] \times f \sqrt{a_{0} y_{*}}
$$

where,

$a_{0}:$ amplitude of oscillating water pressure in water head

$y_{*}:$ the mixed fluid depth

Accordingly, the amount of recovery sand layer during sedimentation time $\Delta t$ is that,

$$
\Delta y_{r c}=V_{r} \times \Delta t
$$

\section{d) Variation of porosity}

The sedimentary sand layer is densified under oscillating water pressure. Therefore, the porosity in the recovered zone changes with the acting cycle number of the oscillating water pressure. According to the analysis on the experimental data ${ }^{1)}$ (pass time; $5 \mathrm{~min} ., 10 \mathrm{~min} ., 100 \mathrm{~min}$. and $1000 \mathrm{~min}$.), the porosity varies with the acting cycle number of the oscillating water pressure in the form of logarithmic function. Because of the absence of measured data during the initial period about 10 seconds after the excitation, it is supposed that the porosity linearly varies with the cycle number of the oscillating pressure. Then, the following formulas are adopted to calculate the porosity for the following analysis. 


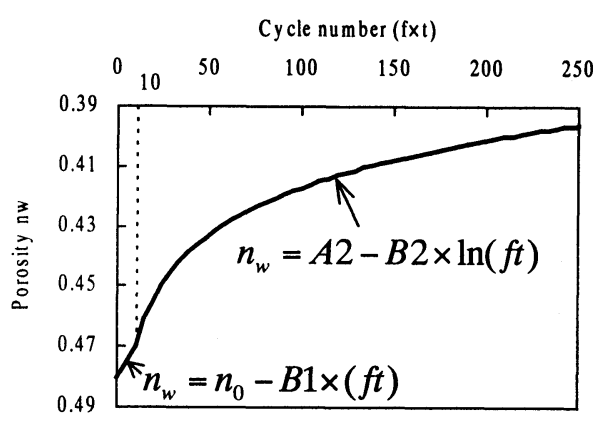

Fig.7 Variation of porosity $n_{w}$ with the cycle number

$$
\begin{aligned}
& n_{w}=n_{0}-B 1 \times(f t) \quad t \leq t_{y} \\
& n_{w}=A 2-B 2 \times \ln (f t) t \geq t_{y}
\end{aligned}
$$

in which,

$n_{0}$ : the initial porosity of sand bed

$f$ : frequency of oscillating water pressure

$t:$ the time for action of oscillating water pressure

$t_{y} \quad$ : time when the mixed fluid depth gets its maximum value.

$B 1, A 2, B 2$ : the coefficients relating to the initial porosity of sand bed $\left(n_{0}\right)$ and the amplitude of the oscillating water pressure on the sand surface.

The variation of porosity with the cycle number is shown in Fig.7.

The densification of sand bed mainly occurs within the zone that sand layer have liquefied. Eq. $(17 a, 17 b)$ were applied in the zone of the recovered sand layer with the progress of sediment interface. The values of $B 1, A 2$ and $B 2$ in the following numerical analysis were decided by referring the initial porosity, final porosity and the cycle number measured in our model test. They are regarded as constant. The influence range of oscillating water pressure on the porosity of sand bed is considered to be the zone from the interface to the depth being equal to amplitude of oscillating water pressure.

In our experiments, the cycle number from the initiation of the excitation, at which the liquefaction depth gets its maximum value, is less than 10 . Considering these experimental data, for simplicity, Eq.(17a) is approximately adopted in the initial 10 cycles, and Eq.(17b) is used after 10 cycles in the following instance of the numerical analysis.

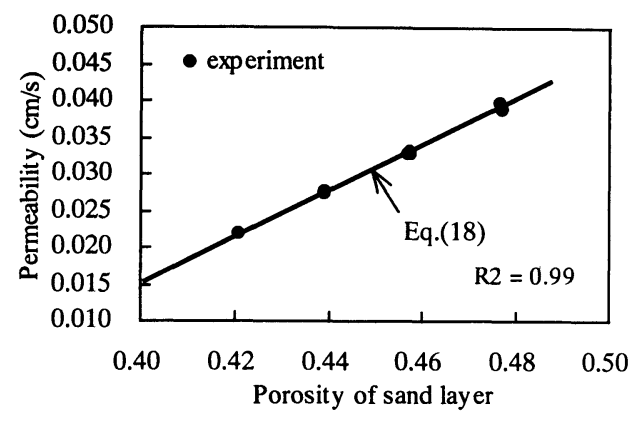

Fig.8 Permeability of sand layer

\section{e) Permeability coefficient of sand layer}

The permeability coefficient of sand bed varies with the variation of porosity in sand bed. The permeability coefficients from our laboratory test on the Toyoura sand $\left(d_{50}=0.25 \mathrm{~mm}\right)$ with different porosity are shown in Fig.8. According to dimensional analysis, the relationship of permeability coefficient of sand bed with porosity of sand bed is obtained from the above experimental data as follows:

$$
\begin{gathered}
k=\left(0.064 \times n_{w}-0.023\right) \sqrt{g d} \\
\left(n_{w}=0.42 \sim 0.48\right)
\end{gathered}
$$

where,

$k \quad$ : permeability coefficient

$n_{w}$ : porosity in sand bed

$g$ : acceleration due to gravity

$d$ : grain size of sand( here, $d=d_{50}$ )

f) Settlement of sand bed surface

The settlement of sand bed surface is found by means of the mass conservation of sand particles with the following formula.

$$
\rho_{s}\left(1-n_{w 0}\right) D_{0}=\int_{s}^{D_{0}} \rho_{s}\left(1-n_{w}\right) d y
$$

where,

$S$ : settlement of sand bed surface at time $t$

$n_{w 0}$ : porosity occupied by water at initial state

$D_{0}$ : thickness of sand bed at initial state

The porosity $n_{a}$ is neglected in Eq.(19).

\section{NUMERICAL SOLUTIONS AND EXPERIMENTAL VERIFICATION}

\section{(1) Method and results of experiment}

The vertically placed cylinder made of resin was used as the vessel of sand layer. Its inner diameter is $8.9 \mathrm{~cm}$ and its height is $326 \mathrm{~cm}$. The column was filled 
with loosely deposited sand to $320 \mathrm{~cm}$ from its bottom, and the water depth above the sand surface was about $100 \mathrm{~cm}$. The detail of apparatus was shown in the former paper ${ }^{12)}$.

The amplitude of oscillating water pressure was about $80 \mathrm{~cm}$ in water head and the frequency was 1.0 $\mathrm{Hz}$. The grain size of sand used in the experiment was $d_{50}=0.25 \mathrm{~mm}$ (Toyoura sand), and its specific weight was 2.65 . The permeability coefficient of sand layer for the initial state was about $0.04 \mathrm{~cm} / \mathrm{sec}$. The porosity $n_{w}$ at the initial state was about 0.48 .

The oscillating water pressure on the sand surface was generated with a generator of oscillating air pressure. The water pressures in the water and in the sand bed were measured by means of pressure transducers attached to the side of the cylinder. Pressures were measured continuously from the beginning of the experiment for 10 minutes long with
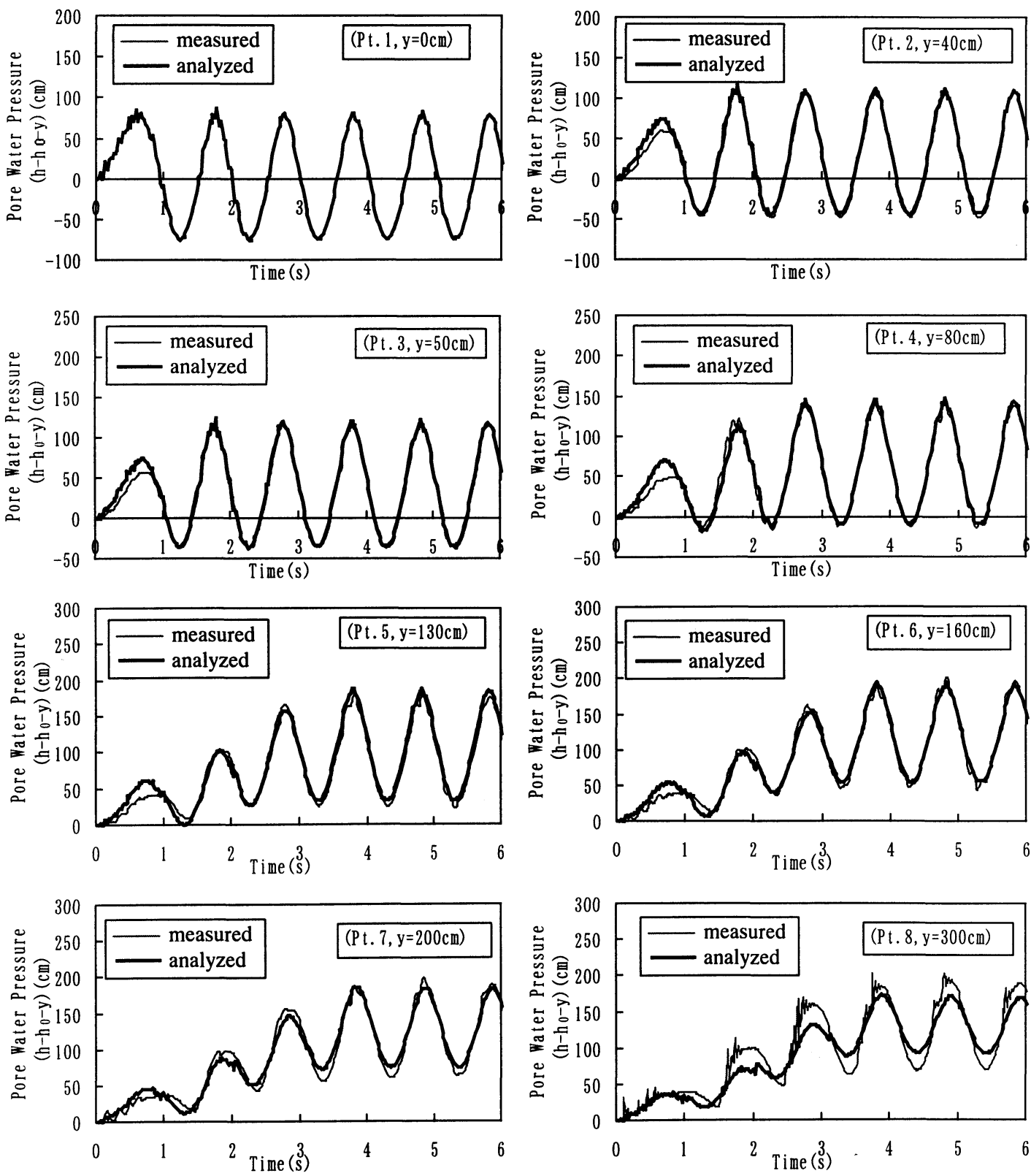

Fig. 9 Pore water pressure measured and numerically analyzed during the initial 6 seconds 

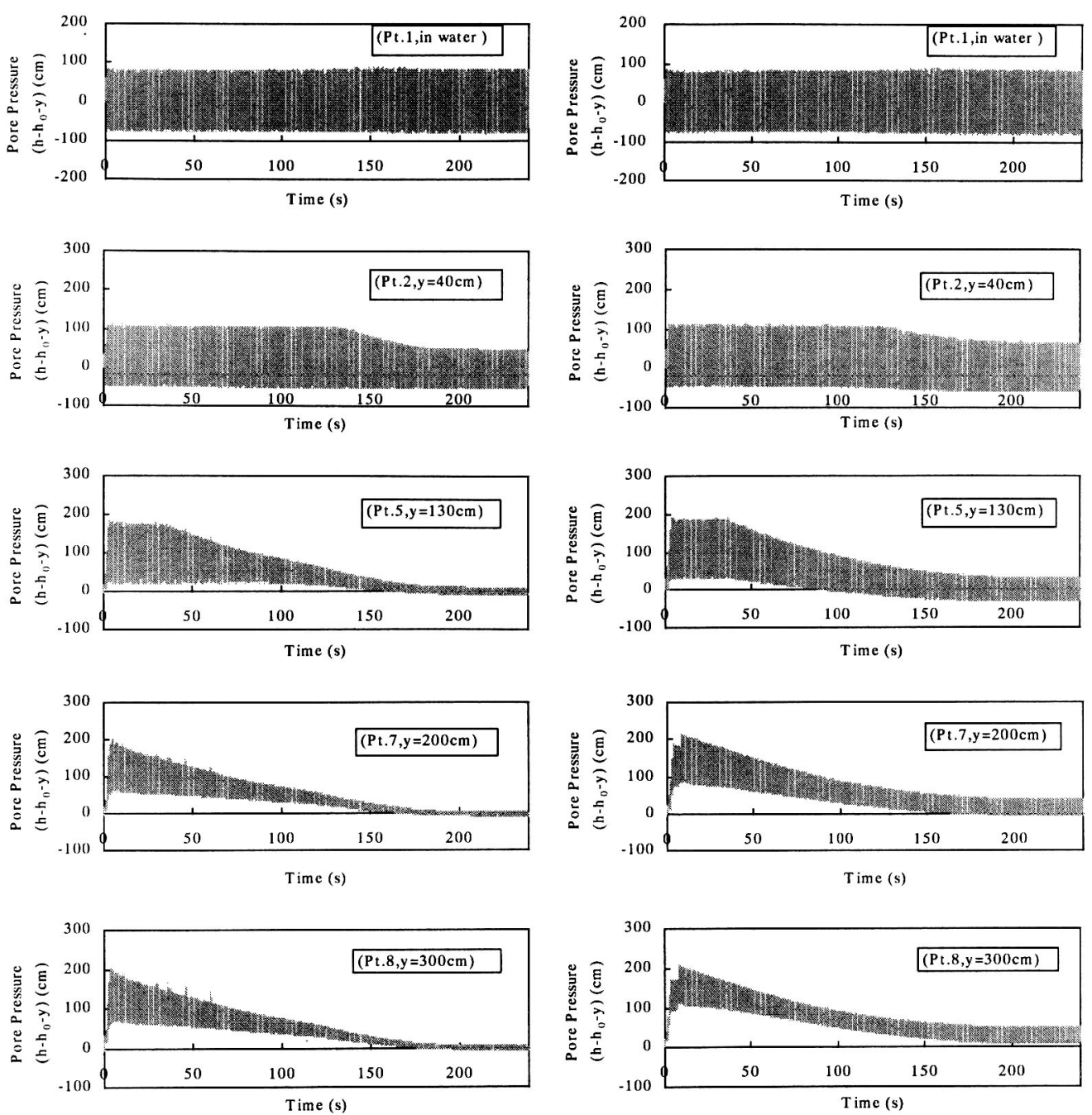

Fig.10 Variation of pore water pressure with time (measured in experiment)

Fig.11 Variation of pore water pressure with time (numerically analyzed)

an interval of 0.02 second.

The pore water pressures measured in the experiment are shown in Fig.9 and Fig.10.

Fig.9 shows the variations of pore water pressures measured at Pt.1 (in water), Pt.2 ( $y=40 \mathrm{~cm}$ ), Pt.3 (y=50cm), Pt.4 (80cm), Pt.5 ( $y=130 \mathrm{~cm})$, Pt.6 $(y=160 \mathrm{~cm})$, Pt.7 $(y=200 \mathrm{~cm}), P t .8(y=300 \mathrm{~cm})$ in the sand bed during the initial 6 cycles.

Fig.10 displayed that the pore water pressures measured at Pt.2 $(y=40 \mathrm{~cm})$, Pt.5 ( $y=130 \mathrm{~cm})$, Pt.7 $(\mathrm{y}=200 \mathrm{~cm})$, Pt. $8(\mathrm{y}=300 \mathrm{~cm})$ vary with time for the period of 250 seconds, respectively.

(2) Numerical solutions by finite element method

The oscillating water pressure measured at Pt.1(in water) in Fig.9 was adopted as the oscillating water pressure in water for the following numerical analysis.

Since we could not detect the exact values of the compressibility of sand layer and the porosity occupied by air, they are assumed in this instance that $\alpha=6 \times 10^{-9}\left(\mathrm{~m}^{2} / \mathrm{N}\right), \quad n_{a}=0.0022$ (the value at a point $30 \mathrm{~cm}$ deep in the sand bed), by referring the relative data used in the past literatures.

In this case, The parameters used in the numerical analysis are given in the Table 1. $\Delta y$ in the above 
table denotes the height of element in numerical analysis.

The pore pressures obtained by numerical solution of the analytical model mentioned above, with finite element method for the same case, are also shown in Fig.9.

In the former analysis ${ }^{12)}$ for initial two cycles of excitation, the sedimentation of sand in the liquefied zone was neglected. In this analysis for 6 cycles, the

Table 1 Parameters used in the numerical analysis case.

\begin{tabular}{|c|c|c|}
\hline Symbol & Adopted value & Unit \\
\hline$n_{0}$ & 0.486 & -- \\
\hline$n_{w}(\mathrm{t}=0)$ & 0.486 & -- \\
\hline$n_{a}$ & 0.0022 & -- \\
\hline$a_{0}$ & 80 & $\mathrm{~cm}$ \\
\hline$f$ & 1.0 & $\mathrm{~Hz}$ \\
\hline$\beta$ & $4.3 \times 10^{-10}$ & $\mathrm{~m}^{2} / \mathrm{N}$ \\
\hline$D$ & 320 & $\mathrm{~cm}$ \\
\hline$\rho_{s}$ & 2.65 & $\mathrm{t} / \mathrm{m}^{3}$ \\
\hline$h_{0}$ & 100 & $\mathrm{~cm}$ \\
\hline$\Delta t$ & 0.02 & $\mathrm{~s}$ \\
\hline$\Delta y$ & 0.53 & $\mathrm{~cm}$ \\
\hline$\alpha$ & $6 \times 10^{-9}$ & $\mathrm{~m}^{2} / \mathrm{N}$ \\
\hline$\alpha_{1}$ & $100 \times \alpha$ & -- \\
\hline$B 1$ & 0.001 & -- \\
\hline$A 2$ & 0.495 & -- \\
\hline$B 2$ & 0.011 & -- \\
\hline$E$ & 33.33 & -- \\
\hline$F$ & 15.0 & -- \\
\hline$M$ & 30.63 & -- \\
\hline$N$ & 16.17 & -- \\
\hline
\end{tabular}

sedimentation of sand in the liquefied zone is taken into consideration. It is clear from Fig.9 that the pore pressure obtained numerically by this model are in good agreement with the experiment results.

For the whole range of excitation, The oscillating water pressure measured at Pt.1(in water) in Fig.10 was adopted as the oscillating water pressure in water for the following numerically analysis. The pore pressures obtained by numerical solution of the analytical model mentioned above, with finite element method for the same case, are also shown in Fig.11.

It is understood from Fig.10 and Fig.11 that the pore pressure obtained numerically by the model can express the variation of experimental pore pressure comparatively well.

Although the amount of damping of pore water pressure obtained from the numerical analysis is slightly smaller than that from the experiment, especially in the latter part of the process, it seems to be proved that the model proposed in this paper is suitable to analyze the progressive liquefaction process, sustaining liquefaction process and the densification process of the first stage of liquefaction.

The variations of the depth of the mixed fluid and the settlement of sand bed surface with time are shown in Fig.12. On the analytical solutions, the maximum depth of the mixed fluid is $166 \mathrm{~cm}$ and the amount of the settlement is $9.5 \mathrm{~cm}$. The observed settlement of sand bed surface at 360 seconds is 9.46 $\mathrm{cm}$. The mixed fluid depth(reference) shown in Fig.12 is determined as follows:

$$
y_{{ }^{\prime} L}=S+\frac{\operatorname{ave}(\tilde{h})}{\left(\rho_{s}-\rho_{w}\right)(1-n)}
$$

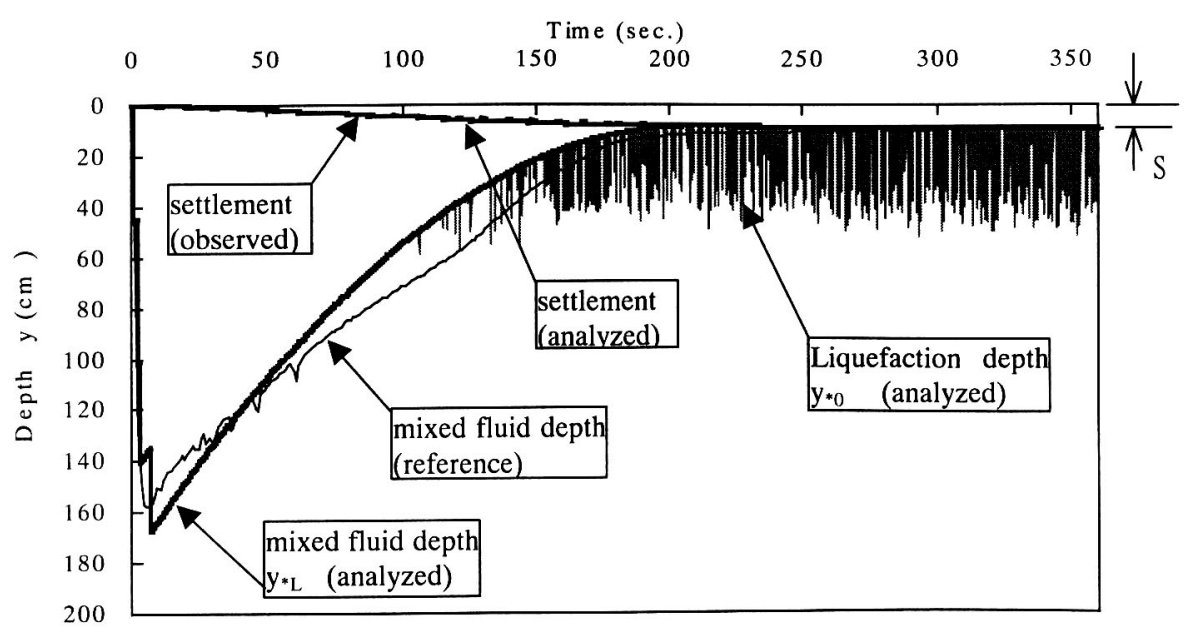

Fig.12 Processes of progressive liquefaction and densification 
where,

$S$ : settlement of sand bed surface measured in the experiment

ave $(\tilde{h}):$ the temporal average of the variation of pore water pressure measured at point (Pt.8 $\mathrm{y}=300 \mathrm{~cm})$ in the sand bed over every wave cycle.

The porosity $n$ in Eq.(20) is substituted by the initial porosity of sand bed, for the values of porosity is not known during the experiment. The curve determined by Eq.(20) is used as a reference curve to understand the variation of the mixed fluid depth in sand bed.

It is clearly shown in Fig.12 that the numerically analyzed settlement at sand bed surface agreed with the observed settlement, and the trend of variation of the mixed fluid depth expressed the progressive liquefaction process and the recovery process (the densification process) fairly well.

The porosity variation of sand bed with cycle number obtained from the numerical analysis case is given in Fig.13. It is understood from Fig.13 that the sand bed gradually densified with the increase of cycle number, and that when the recovery of sand layer from the mixed fluid state reached the surface of sand bed, the densification process were mainly developing in the zone near the surface of sand bed.

We didn't get the measured data of porosity from the experiment at the same time. However, the measured data of porosity after the oscillating water pressure was exerted for 100 minutes, that is, when the experiment was finished, is also shown in Fig.13. it is known that the numerically analyzed result almost well expresses the profile of porosity distribution

\section{CONCLUSION}

In this paper, the progressive liquefaction and densification processes of the loosely deposited sand bed under the oscillating water pressure on the sand surface were investigated theoretically by using the vertically one-dimensional model, and the analytical solutions were verified by the experiment. The conclusion can be drawn as follows:

It is clear that the solutions of the proposed analytical model fairly well reproduced the progressive liquefaction and densification processes of the sand bed in the first stage of liquefaction. But the amount of damping of pore water pressure obtained by the numerical analysis is slightly smaller

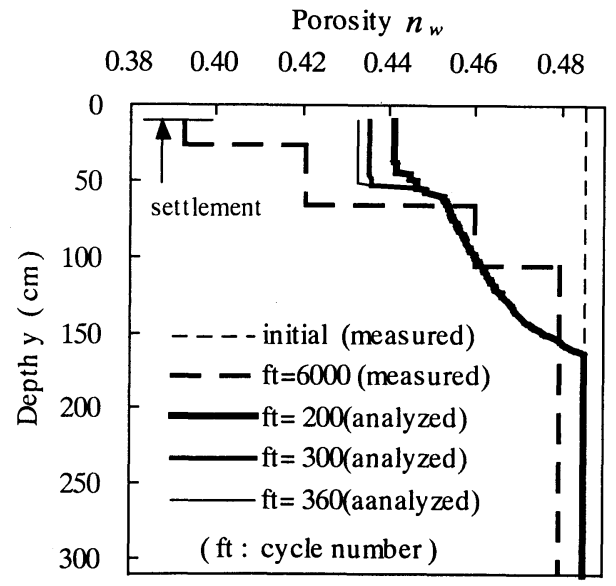

Fig.13 Densification process of sand bed (numerically analyzed )

than that by the experiment.

It is considered that it resulted from the assumed coefficients adopted in the numerical analysis. The values of the compressibility, the yield effective stress and the liquefaction ratio of sand bed are assumed in the numerical analysis. It is necessary to make clear the characteristics of these values in further research.

ACKNOWLEDGMENT: This research was partly supported by a Grant-in-Aid for Scientific Research (C) $(1998,1999$, No.10650508) and (B) (2000, No.12450202) from the Japanese Ministry of Education, Science, Sports and Culture. We are grateful for these supports.

\section{REFERENCES}

1) Nago, H., Maeno, S., Matsumoto, T. and Hachiman, Y. : "Liquefaction and Densification of Loosely Deposited Sand Bed Under Water Pressure Variation", Proceedings of the Third International Offshore and Polar Engineering Conference, Singapore, 6-11 June, 1993.

2) Yamamoto, T., Koning, H. L., Sellmeijer, H. and Hijum, E. : "On the response of a poro-elastic bed to water waves", J. Fluid Mech., Vol. 87, No.1, pp. 193-206, 1978.

3) Madsen, O.S.: "Wave-induced pore pressure and effective stresses in a porous bed", Geotechnique, Vol. 28, No.4, pp.377-393. 1978.

4) Okusa, S. : "Wave-induced stresses in unsturated submarine sediments", Geotechnique, Vol.35, No.4, pp.517-532. 1985.

5) Sakai, T., Hatanaka, K. and Mase, H. : "Applicability of Solutions for Transient Wave-induced Porewater Pressures in Seabed and Liquefaction Conditions of Seabed", Proceedings of JSCE, No.417/2-13, pp.275-283. May, 1990.(in Japanese)

6) Nago, H. : "Liquefaction of Highly Saturated Sand Layer under Oscillating Water Pressure", Memoirs of the School of Engineering, Okayama University, Vol.16, No.1, pp.91- 
104. 1981.

7) Nago, H. and Maeno, S. : "Pore Pressure and Effective Stress in A Highly Saturated Sand Bed Under Water Pressure Variation on Its Surface", Natural Disaster Science, Volume 9, Number 1,pp.23-35. 1987

8) Zen, K., Yamazaki, H. and Watanabe, A. : “ Wave-induced Liquefaction and Densification in Seabed ", Report of the Port and Harbour Research Institute, Vol. 26, No. 4, 1987.(in Japanese)

9) Oka, F., Yashima, A., Shibata, T. and Kato, M. : “ A finite element analysis of liquefaction of seabed due to wave action", Proceedings of the international symposium Geocoast'91, Yokohama, pp. 621-626, 3-6,Sept., 1991.

10) Kuwabara, H. and Tamai, S. : "Wave-induced Elasto- plastic Behavior of Ground around Breakwater ", Proceeding of Coastal Engineering, JSCE, Vol.39, pp.861-865. 1992. (in Japanese)

11) Sekiguchi, H., Kita, K. \& Okamoto, O. : "Response of poro-elastoplastic beds to standing waves". Soils Found, Vol. 35, No. 3, pp. 31-42, 1995.

12) Yu,Y., Maeno, S., and Nago H.: "Progressive Liquefaction Process of Loosely Deposited Sand Bed under Oscillating Water Pressure", Journal of Geotechnical Engineering, JSCE., No.680/III-55,pp.1-14, June, 2001.

(Received July 26, 2001) 